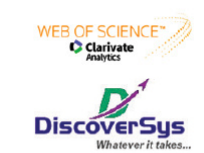

Published by DiscoverSys

\section{The levels of Human Beta Defensin-2 (HBD-2) in premature neonates' feces at Saiful Anwar Hospital, Malang, Indonesia}

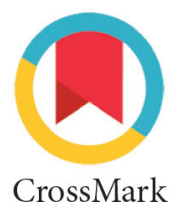

\author{
Eko Sulistijono ${ }^{1}$, Putri Primawardani ${ }^{1{ }^{*}}$, Krisni Subandiyah ${ }^{1}$, Anik Puryatni $^{1}$
}

\title{
ABSTRACT
}

Background: Clinical evidence shows that the etiology of neonatal sepsis is translocation of the digestive tract of premature neonates. Human B-defensor 2 has a protective effect during inflammation and apoptosis. This study aimed to determine the levels of fecal human B-defensus-2 (HBD-2) as an inflammatory biomarker in premature neonates related to nutrition consumption.

Methods: A cohort study design used in thirty-nine premature neonates according to inclusion criteria were collected in January to March 2019 in the neonatology room of RSUD Dr. Saiful Anwar Malang. The levels of premature neonatal feces HBD-2 were taken from all three sample groups on the seventh and fourteenth days and measured by the ELISA method. Data were analyzed using SPSS version 20 for Windows.

Results: The mean levels of HBD-2 premature neonatal feces consuming formula milk alone were higher than other groups $(349.16+67.66$ vs $330.24+44.08$ vs $215.65+51.34)$. There is a relationship between levels of $\mathrm{HBD}-2$ premature neonatal feces with only breastfeeding ( $p=0,005 ; r=0.731)$, breast milk $(p=0,005 ; r=0,727)$ and, formula milk only $(p=0,003 ; r=0,761)$. Conclusion: The levels of HBD-2 in premature neonatal stools who consuming formula milk alone were significantly higher than levels of human HBD-2 premature neonatal stools that consumed only breast milk.
'Department of Child Health, Faculty of Medicine, Brawijaya University, Saiful Anwar Hospital, Malang, Indonesia
*Corresponding to: Putri Primawardani; Department of Child Health, Faculty of Medicine, Brawijaya University, Saiful Anwar Hospital, Malang, Indonesia; putriprimawardani@gmail.com
Received: 2020-02-23 Accepted: 2020-04-10 Published:2020-05-07

\section{INTRODUCTION}

Neonatal sepsis occurs in premature neonates with the increasing prevalence from $2 \%$ in neonates with gestational age 32 to 37 weeks (moderately preterm infants), $10-20 \%$ in neonates with gestational age 28 to 32 weeks (very preterm infants), and up to $30-40 \%$ in neonates with gestational age $<28$ weeks (extremely preterm infants). ${ }^{1,2}$ The protective effect from neonatal sepsis in neonates who are breastfed is likely occurred due to variety of complementary and innate defense factors found in human milk. ${ }^{3}$ Human Beta Defensin-2 (HBD-2) is one of the defense factors secreted in the gastrointestinal epithelium and is associated with inflammatory reactions. Human Beta Defensin-2 (HBD-2) shown to have a protective effect during inflammation and able to stimulate epithelial repair in the digestive tract. $^{4}$

Research by Corebima in 2017 found a relationship between enteral nutrition toward fecal HBD-2 levels, suggests that fecal HBD-2 levels are significantly lower in neonates who consume breast milk compared to neonates who consume breast milk mix with formula milk or formula milk only. ${ }^{5}$ Although gastrointestinal infection is one of the main causes of morbidity in premature neonates, definitive procedure to establish the diagnosis is still challenging because of clinical conditions and examinations show relatively similar results with clinical manifestations due to problems outside the gastrointestinal. ${ }^{6}$

One strategy that can be done to reduce morbidity and mortality due to digestive tract infections is to develop non-invasive biomarkers that are able to detect gastrointestinal inflammation before clinical symptoms appear. ${ }^{3}$ Research conducted by Campeotto et al., 2010 shows that HBD-2 is very easily measured and is always detected in the feces of newborns and shows protective effect in the first week of life. Until now, research comparing the provision of enteral nutrition with fecal HBD2 in Indonesia is still limited. Therefore, this study aims to determine the level of fecal HBD-2 as an inflammatory biomarker in premature neonates who consume breast milk only, formula milk 
only, and also breast milk mix with formula milk in neonates aged 7 and 14 days at Saiful Anwar Hospital, Malang, Indonesia.

\section{MATERIAL AND METHOD}

This cohort study design conducted in the neonatology unit of the Saiful Anwar General Hospital (RSSA) Malang and in Physiology Laboratory Faculty of Medicine, Universitas Brawijaya, Malang for three months.

The study population were preterm neonates (gestational age less than 32 weeks) who were treated in the RSSA perinatology room from 1 January to 29 March 2019, APGAR score 5 at the fifth minute, and without congenital abnormalities, with number of samples 13 for each group.

Sample was divided into three groups namely feces of premature neonates who consumed only

Table 1. Characteristic of study sample

\begin{tabular}{|c|c|c|c|}
\hline Characteristic & Breastmilk & $\begin{array}{c}\text { Breastmilk } \\
\text { mix with } \\
\text { formula milk }\end{array}$ & $\begin{array}{l}\text { Formula } \\
\text { milk }\end{array}$ \\
\hline \multicolumn{4}{|l|}{ Gender, (n) } \\
\hline - Male & $6 / 13$ & $4 / 13$ & $4 / 13$ \\
\hline - Female & $7 / 13$ & $9 / 13$ & $9 / 13$ \\
\hline $\begin{array}{l}\text { Gestational age (week), } \\
\text { median (min - max) }\end{array}$ & $30(25-32)$ & & \\
\hline$\bullet<28$ & $2 / 13$ & $1 / 13$ & - \\
\hline - $28-30$ & $4 / 13$ & $6 / 13$ & $5 / 13$ \\
\hline - $30-32$ & $7 / 13$ & $6 / 39$ & $8 / 13$ \\
\hline Birth weight (gram), mean (SD) & $1553.8( \pm 430.7)$ & $1459.7( \pm 406.5)$ & $\begin{array}{c}1010 \\
( \pm 506.4)\end{array}$ \\
\hline Birth length, mean (SD) (cm) & $39.2( \pm 4.6)$ & $39.5( \pm 2.9)$ & $40.9( \pm 4.0)$ \\
\hline $\begin{array}{l}\text { Head circumference, mean }(\mathrm{SD}) \\
(\mathrm{cm}\end{array}$ & $28.2( \pm 2.1)$ & $27.8( \pm 1.7)$ & $28.4( \pm 1.8)$ \\
\hline Oxygen therapy (n) & $6 / 13$ & $7 / 13$ & $5 / 13$ \\
\hline \multicolumn{4}{|l|}{ Mode of delivery (n) } \\
\hline • Normal & $7 / 13$ & $3 / 13$ & $3 / 13$ \\
\hline - Sectio caesarian & $6 / 13$ & $10 / 13$ & $10 / 13$ \\
\hline \multicolumn{4}{|l|}{ History of pregnancy (n) } \\
\hline - Preeclampsia & $3 / 13$ & $4 / 13$ & $6 / 13$ \\
\hline - Eclampsia & - & - & $1 / 13$ \\
\hline - Premature rupture of the & $3 / 13$ & $6 / 13$ & $6 / 13$ \\
\hline $\begin{array}{l}\text { membrane } \\
\text { - Gemelli }\end{array}$ & $2 / 13$ & - & - \\
\hline \multicolumn{4}{|l|}{ Clinical condition (n) } \\
\hline - Respiratory distress & $6 / 13$ & $6 / 13$ & $6 / 13$ \\
\hline • Vomiting & $10 / 13$ & $9 / 13$ & $9 / 13$ \\
\hline - Enlarged abdomen & $9 / 13$ & $9 / 13$ & $5 / 13$ \\
\hline Antibiotic use & $7 / 13$ & $9 / 13$ & $11 / 13$ \\
\hline
\end{tabular}

breast milk, breast milk and formula milk, and formula milk only in neonates aged 7 and 14 days. Sample collected using a spatula with amount 100 $\mathrm{mg}$, then transferred to a container. Stool samples delivered in less than 30 minutes using a container that can maintain a stable temperature.

HBD-2 levels in stool samples were measured by the ELISA method. ELISA examination uses the HBD2 Immunoassay human kit in according to instructions on the kit product. Human Beta Defensin 2 was measured using spectrophotometry at $450 \mathrm{~nm}$ wavelength.

Data collected from the results of HBD2 measurements from each group. Data were analyzed using a normality test then a comparative test conducted to lookup significant differences in each group and processed using SPSS software.

\section{RESULTS}

Comparison of neonatal sex between male and female respectively 14 and $25(\mathrm{p}=0.64)$, most of the study samples delivered through caesarian section (26/39), median gestational age of samples was 30 weeks with range from of 25 to 32 weeks. Mean birth weight in the neonatal group who consumed breastmilk was $1553.8 \pm 430.7$ grams, breastmilk and formula milk group was $1459.7 \pm 406.5$ grams, and only formula milk group was $1010 \pm 506.4$ grams $(\mathrm{p}=0.84)($ Table 1$)$.

From 39 samples that observed for 14 days, 27 samples were recorded using antibiotics, with duration 5 days in 3 samples, 7 days in 14 samples and 14 days in 10 samples. Antibiotic usage based on clinical symptoms with respiratory complaints obtained in 18 samples, digestive complaints such as vomiting (8 samples), enlarged abdomen (3 samples) as well as vomiting and enlarged abdomen (15 samples). Vomiting were found earliest on the third day of treatment in the breast milk mix formula group samples, while enlarged stomach were found earliest on the fifth day of treatment in the formula milk group only.

We obtained mothers with risk factors for preeclampsia in 13 samples, eclampsia in 1 sample, premature rupture of membranes (less than 18 hours) in 15 samples, and 2 samples with twin pregnancy. Each characteristic was analyzed using chi-square and obtained p-value $>0.05$.

Highest HB-2 level was found in preterm neonatal group who consumed formula milk on the fourteenth day with HB2 level $492 \mathrm{ng} / \mathrm{mL}$, and the lowest level was found in the seven-day preterm neonate group who consumed breast milk only which was $158.27 \mathrm{ng} / \mathrm{mL}$.

In preterm neonatal group who consumed breast milk only, interval of fecal HBD-2 levels at 

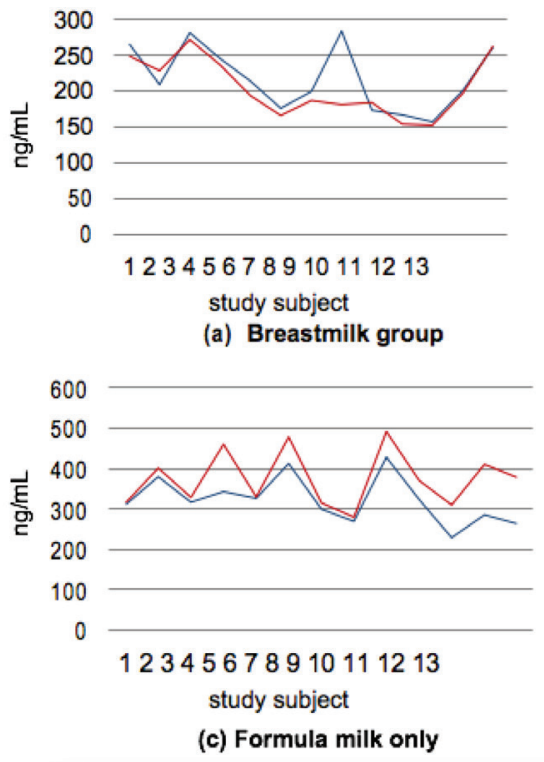

Figure 1. Level of of fecal HBD-2 in premature neonatal with (a) breastmilk only; (b) breastmilk mix with formula milk; and (c) formula milk only on seventh and fourteenth day.

Note: Level of fecal HBD-2 in breastmilk group decreased in the fourteenth day compared with the seventh day. While in breastmilk mix with formula milk group level of fecal HBD-2 increased in the fourteenth day. (a) group of premature neonates who consumed breastmilk only, (b) group of premature neonates who consumed breastmilk mix with formula milk, (c) group of premature neonates who consumed formula milk only.

\section{Table 2. Comparative test result of fecal neonatal HBD-2}

\begin{tabular}{lcc}
\hline \multicolumn{1}{c}{ Variable } & Mean(SD) (ng/mL) & p-value \\
\hline Breastmilk only & $215.65 \pm 51.34$ & \\
Breastmilk mix with formula milk & $330.24 \pm 44.08$ & $0.00^{*}$ \\
Formula milk only & $349.16 \pm 67.66$ & 0.395 \\
\hline
\end{tabular}

Tabel 3. Fecal HBD-2 during seventh- and fourteen-days observation

\begin{tabular}{lccc}
\hline & \multicolumn{2}{c}{ Day Observation } & \multirow{2}{*}{ P value } \\
\cline { 2 - 3 } & $\mathbf{7 ~ d a y}$ & $\mathbf{1 4}$ day & \\
\hline Breastmilk only & $226.85 \pm 59.75$ & $204.47+40.63$ & 0.039 \\
Breastmilk with formula milk & $308.81 \pm 39.96$ & $351.66+38.18$ & 0.00 \\
Formula milk only & $322.58 \pm 58.82$ & $375.73+68.12$ & 0.015 \\
\hline
\end{tabular}

Tabel 4. Correlation between HBD-2 level in fecal premature neonates

\begin{tabular}{cccccc}
\hline $\begin{array}{c}\text { Breastmilk } \\
\text { only }\end{array}$ & $\begin{array}{c}\text { Breastmilk } \\
\text { mix with } \\
\text { formula milk }\end{array}$ & $\begin{array}{c}\text { Formula milk } \\
\text { only }\end{array}$ \\
\hline$r$ & $p$-value & $r$ & $p$-value & $r$ & $p$-value \\
\hline
\end{tabular}

$\begin{array}{lllllll}\text { Day of observation } & 0.731 & 0.005 & 0.727 & 0.005 & 0.761 & 0.003\end{array}$

seven days (158.27-2284.77 ng/mL) was higher than fecal HBD-2 interval at fourteen days (152,77$249.77 \mathrm{ng} / \mathrm{mL}$ ), although two samples was found to have fecal HBD-2 levels higher on the fourteenth day $(228.02 \mathrm{ng} / \mathrm{mL}$ and $184.52 \mathrm{ng} / \mathrm{mL}$ ) compared to the seventh day $(210.27 \mathrm{ng} / \mathrm{mL}$ and $174.52 \mathrm{ng} / \mathrm{mL})$.

Whereas in preterm neonatal group who consumed breast milk and formula milk, interval of HBD-2 levels in premature neonatal feces on the fourteenth day (304.27-4.47 ng/mL) was higher than the seventh day (222.77-391.02 ng/ $\mathrm{mL}$ ). Contrast with preterm neonatal group who consumed formula milk only (seventh day: 230.77$426.77 \mathrm{ng} / \mathrm{mL}$, fourteenth day: $311.22-492.27 \mathrm{ng} /$ $\mathrm{mL}$ ) (Figure 1).

The preterm neonate group with only formula milk consumption had a higher mean fecal HBD2 than the other groups $(349.16 \pm 67.66)$, but it was not significantly different from the preterm neonate group who consumed breast milk with formula milk $(p=0.395)$. In contrast, the mean of fecal HBD-2 levels of premature neonatal consumed breastmilk only were significantly different ( $p$ $=0.00$ ) against the other two groups (Table 2). Furthermore, to determine the difference in mean of fecal HBD-2 level from the three groups on seventh and fourteenth days, a paired $\mathrm{T}$ test was performed as follows (Table 3). From statistical analysis in table 3 , can be concluded that there are differences in fecal HBD-2 level in the three groups of preterm neonates on the seventh and fourteenth days, which shows the differences in the average of the fecal HBD-2 level of the seventh and fourteenth premature neonates in each group (figure 2). Analysis and correlation test showed a positive relationship between the levels of fecal HBD-2 level in preterm neonates with consumption of breastfeeding, breastmilk with formula milk, and formula milk only $(\mathrm{r}=0.498, \mathrm{p}<0.05)$.

Fecal HBD-2 levels in the preterm neonate group consuming breastmilk only showed statistically significant relationship on the seventh and fourteenth days with $\mathrm{p}=0.005$ and $\mathrm{r}$ count of 0.731 . Likewise, the group of premature neonates who consumed breastmilk mix formula milk and formula milk only showed a statistically strong significant relationship on the seventh and fourteenth days $(\mathrm{p}=0.005$ and $\mathrm{p}=0.003)$ (Table 4$)$.

\section{DISCUSSION}

The lowest fecal HBD-2 level detected in this study was 158.27 , in group of seven-day premature neonates who consumed breast milk only. This level is similar to a previous study by Campeotto 
et $\mathrm{al}^{3}$, which described levels of fecal HBD-2 in 7 days old healthy neonates was 30-470. This study proves that there are differences in the mean levels of HBD-2 premature neonatal feces in the three groups that are statistically significant. These results are in accordance with preliminary research by Corebima $^{5}$ which found fecal HBD-2 levels of neonatal breastmilk group were much lower than those in the formula milk group. The highest levels of HBD-2 were found in fourteen days old neonates who consumed formula milk only, which was 492 . This value was higher than HBD-2 levels in healthy preterm neonates in study by Campeotto et $\mathrm{al}^{3}$ which were 30-54 and included in the levels HBD2 neonates who experienced intestinal distress in the same study, 2-1271. When compared with study by Jenke et $\mathrm{al}^{7}$ the highest fecal HBD-2 level in this study was four times (5-10). Fecal HBD-2 levels related to the bactericidal effect, Routsias et $\mathrm{al}^{8}$ found levels of fecal HBD-2 levels that can kill bacteria that sensitive to antibiotics are 3.25-4.5 $\mathrm{mcg} / \mathrm{mL}$, while levels that needed to kill wild type bacteria is $3.9-9.35 \mathrm{mcg} / \mathrm{mL}$. In addition, a study by Baricelli et $\mathrm{al}^{9}$ showed antimicrobial activity was $0.25 \mathrm{mcg} / \mathrm{mL}$ for S.mercescen, $0.5 \mathrm{mcg} / \mathrm{mL}$ for P. aeruginosa, and $4 \mathrm{mcg} / \mathrm{mL}$ for Acinobacter baumannii. Levels of HBD-2 that stimulated from intestine are still too low to achieve a bactericidal effect in severe infections, in this case breastmilk plays a role in increasing HBD-2 levels, while the HBD-2 content in breastmilk is $0.31-19.12 \mathrm{ng} / \mathrm{mL}$ in colostrum and $52,65-182.29 \mathrm{pg} / \mathrm{mL}$ in mature breastmilk. These results differ from studies by Markus et $\mathrm{al}^{10}$ and Campeotto et $\mathrm{al}^{3}$ which showed levels of HBD-2 feces were not affected by nutrition.

The differences results are possible due to the uneven sample size in each nutrition group in previous studies. Average level of HBD-2 in premature neonatal feces of formula milk group only showed no statistically significant difference with the average level in group breast milk mix with formula milk $(\mathrm{p}=0.344)$, but it was significantly different compared to the breastmilk only group. Same with Arisanti \& Wibowo's research ${ }^{11}$ proves that levels of stool inflammation markers in infants who consume breastmilk and formula milk are not significantly different than those who consume formula milk only. In addition, a study by Corebima ${ }^{5}$ also showed levels of HBD-2 neonatal feces which consume formula milk combine with breastmilk or not, did not show significant differences. Conversely when compared with the breastmilk group showed a significant difference. This can be explained by a study conducted by Willems et a ${ }^{12}$ that formula feeding can induce proinflammatory factors even though clinical signs of inflammation have not been found, whereas breastmilk has a role in suppressing inflammation including in infant gastrointestinal. Additionally, breast milk is also containing complete, balanced and high-quality nutritional content which ensures optimal infant growth and development. ${ }^{13}$

In the breastmilk group there was a decrease in levels of fecal HBD-2 on the fourteenth day compared to seven day which was significantly different and strongly related. A previous publication by Campeotto et $\mathrm{al}^{3}$ explained the levels of fecal HBD-2 of healthy preterm infants aged 14 days old decreased significantly compared to seven days old and remained until the 30th day. Decreased levels of fecal HBD-2 indicate reduced inflammatory reactions, especially in the gastrointestinal of infants. This is in accordance with observations by Bering ${ }^{14}$ in neonates aged 7 days who consume breastmilk only showed a reduced inflammatory reaction. Because breastmilk is able to protect the baby's intestines by stimulating the immune system or provide a substrate related to the development of beneficial intestinal microbiota, especially in the first week of life. In line with research by Bhatia ${ }^{15}$ breastfeeding alone can reduce the incidence of inflammation of the digestive tract by $79 \%$, this value is significantly different when breastfeeding is combined with formula milk, both with breastmilk composition $>50 \%$ and $<50 \%$ breast milk composition, which is only able to reduce $3.2-10 \%$ inflammation of the digestive tract. Sisk et a ${ }^{16}$ in his research proved that inflammation of the digestive tract can decrease by six times in infants who consume breastmilk in the first 14 days of life.

However, there were two samples with HBD 2 levels with fourteenth day higher than the seventh day. This can be due to confounding factors that affect outcomes such as the possibility of bacteria growing when storing breast milk prior to perinatology unit, research by Levebvre ${ }^{17}$ describes that contamination of breastmilk could happened and result in morbidity in neonates, bacteria number $>10^{3}$ is associated with an increased incidence of food intolerance and if bacterial count $>106$ colonies $\mathrm{U} / \mathrm{mL}$ associated with the occurrence of sepsis. In addition, samples using orogastric tube have been shown to have bacterial counts approaching 106 colonies $\mathrm{U} / \mathrm{mL}$.

Consumption of breast milk mix formula milk and formula milk only is statistically proven to be related to average level of of HBD-2 neonatal feces, on the fourteenth day with higher levels than the seventh day. Incidence of inflammation of digestive tract is much higher in infants who consume formula milk only compared to formula milk mix with breast milk or breastmilk only. ${ }^{18}$ Formula 
feeding increased the incidence of inflammation by $15 \%$ and death by $8 \%$. Also described, every $10 \%$ increase volume of formula milk increases the risk of infection by $17.9 \% .^{19}$

Based on correlation statistical tests of increased levels of fecal HBD-2 in the breastmilk group mix with formula milk, and formula milk only on the seventh day and the fourteenth day was $53-58 \%$, which means about $42 \%-47 \%$ caused by factors other than the provision of nutrition. Increased fecal HBD-2 level is associated with increased inflammatory response. Some factors that can increase inflammatory response are respiratory distress, prolonged antibiotics, skin diseases, etc.

There are several limitations in this study; (1) samples obtained by consecutive sampling with limited research time, this can affect the representation of research samples to a limited general population; (2) there are still some confounding factors that are difficult to avoid and can influence the results in this study, such as the way of storing and transporting breastmilk from mothers to perinatologists, orogastric tube use, administration of antibiotics, and treatment rooms in perinatology (infectious or non-infectious) during observations where presents a risk of transmission of different nosocomial bacteria; (3) measurement of fecal HBD-2 parameters is only done twice (age seven days and fourteen days), so it is not known for certain patterns of changes in neonatal fecal HBD-2 levels; (4) this study did not measure HBD-2 meconium levels, so it is not known whether the characteristic variability during maternal pregnancy influences the inflammatory process on the first day of birth; (5) antiinflammatory mechanism is also played by other induced anti-inflammatory cytokines, which can influence the level of assessed HBD-2.

\section{CONCLUSION}

Level of human beta defensus-2 in premature neonatal feces that consumed breastmilk only on the seventh day were higher than the fourteenth day. Whereas levels of human beta defensus-2 in premature neonatal feces consuming breastmilk mix formula milk and formula milk only on the seventh day were lower than the fourteenth day.

\section{SUGGESTION}

Further studies need to examine the clinical characteristics of mothers which can affect human beta defensus- 2 in neonatal feces (nutritional intake, immunological status, chronic preconception disease, and so on).

\section{ETHIC}

This research has been approved by the RSSA ethics committee with letter number: 400 /010/K.3/302/2019.

\section{CONFLICT OF INTEREST}

None

\section{FUNDING}

All funding which were contributed to the research and the publish manuscript were received by the authors

\section{AUTHOR CONTRIBUTION}

All authors have contributed to all process in this research, including preparation, data gathering and analysis, drafting and approval for publication of this manuscript.

\section{REFFERENCE}

1. Stoll BJ, Hansen N, Fanaroff AA, Wright LL, Carlo WA, Ehrenkranz RA, Lemons JA, Donovan EF, Stark AR, Tyson JE, Bauer CR, Korones SB, Shankaran S, Laptook AR, Stevenson DK, Papile L, and Poole WK. 2002. Late-onset sepsis in very low birth weight neonates: the experience of the NICHD Neonatal Research Network. Pediatrics; 110: 285-291.

2. Spearman PW, Camacho-Gonzalez A, Stoll BJ. 2013. Neonatal infectious diseases: evaluation of neonatal sepsis. Pediatr Clin North Am; 60: 367-389.

3. Campeotto F, Baldassarre M, Laforgia N, Viallon V, Kalach N, Amati L, Butel MJ, Dupont C, Kapel

4. N. 2010. Fecal Expression of Human Beta Defensin 2 following Birth. Neonatology; 98:365-369.

5. Otte JM, Werner I, Brand S, Chromik AM, Schmitz F, Kleine M, Schmidt WE. 2008. Human Beta Defensin 2 Promotes Intestinal Wound Healing. Journal of Cellular Biochemistry 104: 2286-2297.

6. Corebima B. 2017. Kadar Human Beta Defensin dalam tinja dan pola mikrobiota saluran cerna pada neonatus kurang bulan yang mendapat ASI, susu formula, maupun kombinasi. Fakultas Kedokteran Universitas Indonesia

7. Avula S, Smith LN, Monga R, Lockwood L, Kadrofske M. 2017. Stool Biomarkers to Diagnose Necrotizing Enterocolitis in Preterm Infants: A Pilot Case-Control Study. Pediatrics; 140(1):1-7.

8. Jenke AC, Zilbauer M, Postberg J, Wirth S. 2012. Human-defensin 2 expression in ELBW infants with severe necrotizing enterocolitis. Pediatr Res;72:51320.

9. Routsias JG, Karagounis P, Parvulesku G, Legakis NJ, Tsakris A. 2010. In Vitro Bactericidal Activity of Human Beta Defensin 2 againts Nosocomial Strain. J.peptide; 31: 1654-1660.

10. Baricelli J, Rocafull MA, Vázquez D, Bastidas B, Báez-Ramirez E, Thomas LE. 2015. Beta- defensin-2 
in breast milk displays a broad antimicrobial activity against pathogenic bacteria. J Pediatr (Rio J); 91:3643.

11. Markus R, Georg H, Michael G, Thorsten F, Anja T, Tobias W, Henrik K. 2010. Influence of Gestational Age, Caesarean Secation, and Type of Feeding on Fecal Human beta Defensin 2 and Tumor Necrosis Factor Alfa. Journal of Pediatric gastroenterology and nutrition; 51(1): 103-105

12. Arisanti D, Wibowo S. 2019. Fecal Calprotectin Level of Breast Milk-Formula vs Formula Feeding in Preterm and Low Birth Weight Neonates with Necrotizing Enterocolitis. Journal of Tropical Life Science; 9(1): 29-33.

13. Pramitasari, P.A., Sidiartha, I.G.L., Pratiwi, I.G.A.P.E. 2019. The effect of storage on energy, carbohydrate, fat, and protein content of breast milk. Bali Medical Journal 8(1): 59-62. DOI: 10.15562/bmj.v8i1.823

14. Bering SB. 2018. Human Milk Oligosaccharides to Prevent Gut Disfunction and Necrotizing Enterocolitis in Preterm Neonates. Nutrients; 10(10): 1461
15. Willems R, Rybicki V, Jiang P, Sangild PT, Shen RL, Hensel KO, Wirth S, Postberg J, Jenke AC. 2015. Introduction of formula feeding induces structure in the intestine of preterm pigs. Mol cell pediatr; 2(1): A6.

16. Bhatia J. 2013. Human milk and the prematur infant. Ann Nutr Metab; 62 (3): 8-14.

17. Sisk PM, Lovelady CA, Dillard RG, Gruber KJ, O'shea TM. 2017. Early human milk feeding is associated with a lower risk of necrotizing enterocolitis in very low birth weight infants. Journal of perinatology; 27: 428-433.

18. Levebvre F, 1990. Breast Feeding Among Mother of Low Birth Weight Infants. 1990. Can Fam Physician; 36: 1533-1536.

19. Abram SA, Schanler RJ, Lee ML, Recthman DJ. 2014. Greater mortality and morbidity in extremely preterm infant fed a diet containing cow milk protein products. Breastfeeding medicine; 9(6): 281-285.

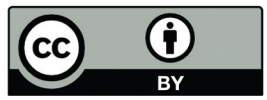

This work is licensed under a Creative Commons Attribution 